\title{
A Machine Learning Approach for Fault Detection in Brushless Synchronous Generator Using Vibration Signals
}

Mehdi Rahnama ${ }^{1}$, Abolfazl Vahedi ${ }^{1 *}$, Arta Mohammad Alikhani ${ }^{1}$, Allahyar Montazeri ${ }^{2}$

${ }^{1}$ Department of Electrical Engineering, Center of Excellence for Power System Automation and Operation, Iran University of Science and Technology (IUST), Narmak 16846, Tehran, Iran.

${ }^{2}$ Engineering Department, Lancaster University, Bailrigg, Gillow Avenue, LA1 4YW, Lancaster, UK.

*avahedi@iust.ac.ir

\begin{abstract}
In order to maintain continuous production and to avoid the maintenance cost increment in power plants, it is important to monitor the condition of equipment, especially the generator. Regarding the impossibility of direct access to rotating diodes in brushless synchronous generators, the condition monitoring of these elements is very important. In this paper, a novel fault detection method is proposed for the diode rectifier of brushless synchronous generator. At the first stage of this method, the vibration signals are recorded and feature extraction is performed by calculating the relative energy of discrete wavelet transform components. Multiclass support vector machine (MSVM) is used for classification, and the best mother wavelet and number of decomposition level are chosen based on classification performance. To enhance the performance of the classification, a modified sequential forward subset selection approach is included by which the best statistical features are selected. In this approach, besides selecting the best subset of statistical features, the classification parameter is tuned according to the selected subset to achieve the best performance. The result of the proposed method is eventually compared with those results of classification performance using conventional subset selection. Experimental results show that the proposed method can detect rectifier faults effectively.
\end{abstract}

\section{Introduction}

Condition monitoring of the generators plays an important role in the industry as one small fault may lead to system frustration. Therefore, fast fault detection is a critical issue. The aim of this paper is to detect faults on the rotating rectifier of the brushless synchronous generators. Since the direct access to the rectifier bridge is not possible in these types of generators, a method must be considered in which the fault can be detected without any direct contact or access to the faulted part, and it is very arduous. The vibration signals are monitored almost in all generators in power plants, and therefore using these signals leads to minimum cost for protection systems modification in power plants. Besides the mentioned advantages, they are measurable for all load conditions for example, the generator current is zero at No load conditions, while diode can be damaged under these conditions. The source of vibration in a rotary electric machine is divided into three general groups including electromagnetic sources, mechanical sources, and hydrodynamic sources [1]. An electrical fault in the rectifier in brushless synchronous generator affects the waveform of the field of the machine and consequently effects the electromagnetic performance of the machine. Therefore, it is expected that the vibration behavior of the brushless synchronous machine changes when a fault occurs in its rectifier.

The fault detection in which there is no need to direct access to the faulted part has been investigated in some literature and some processes are proposed. In the articles, the fault detection is carried out using acoustic signals [2-5], vibration signals [6-11], some other types of signals [12-15], and the combination of some signals [16-20]. The KNN method is utilized to classify the short-circuit fault in the main winding and auxiliary coil of the single-phase induction motor using acoustic signals [2]. Shaft angular misalignment detection is carried out under varying operational conditions using acoustic emission technique and Fourier analysis in [3]. In [4] bearing defects detection of rotary machines using acoustic signals in different signal-to-noise ratio conditions has been investigated based on wavelet packet transform which has good performance in terms of low signal to noise. In [5] using audible noise recorded by smartphone an approach is proposed for induction machine fault detection. In [6] empirical mode decomposition technique is used to analyze the vibration signals of bearing defects since the vibration signals are non-stationary. In this article for the feature extraction of the signals, the statistical information is used and in order to identify the pattern, the neural network is utilized. Helicopter main gearbox planetary bearing fault diagnosis is studied in [7] in which the envelope analysis and kurtogram were performed on vibration signals. Footprint analysis of Hilbert transform along with the neural network are used for ball bearings fault classification in [8]. The vibration of the transformer coil is modeled during mechanical faults that by analyzing the vibrations, the defects can be detected [9]. The energy and Shannon entropy of continuous wavelet transform of the vibration signals are used for the piston scuffing fault detection in the internal combustion engines [10]. Using vibration signals from journal bearings and wavelet transformation, some induced faults on journal bearing are classified by artificial neural network [11] The motor current is decomposed into the intrinsic mode function components by empirical mode decomposition technique and the signals which are similar to the main signal are removed, then the rest of the components are used to extract the feature for induction motor bearing defect detection [12]. The wavelet decomposition and statistical features of the guided ultrasonic wave are extracted to analyze faults on thick steel based on support vector machine (SVM) 
[13]. Detection of synchronous generator bearing defects is performed by calculating the energy of the stator current signals [14]. Short circuit fault on synchronous generator filed winding is investigated in [15] and twin signal sensing is proposed for the fault detection. A fault detection method for internal turn-to-turn short circuit fault on the winding of the rotor and the coil of the stator by external magnetic flux density and external housing vibration signals is proposed in [16]. The hypoid gear fault has been evaluated utilizing sound and vibration signals and a differential waveform has to detect the fault [17]. Mechanical and electrical faults detection of wind turbines has been investigated using the generator output power and rotational speed as well as continuous wavelet transform [18]. Simultaneous analysis of the stray flux and frame vibration of the synchronous machine have been used for a nondestructive and cheap method to detect short-circuit fault on the rotor winding of the synchronous machine [19]. Based on analysis of the modal voltage and the modal current of the stator, an approach is proposed in [20] for detection of induction motors stator turn-faults.

Due to advantages of vibration signal analysis, in this paper, using vibration signals, we propose a strategy for detecting and classifying such rectifier bridge faults in brushless synchronous generator with the enhanced classification accuracy utilizing the wavelet transform and a modified sequential forward subset selection approach applied to the time-domain (statistical) features. Here the search is done over all parameters, nevertheless in case of a large number of parameters evolutionary algorithm can be used at this stage [21, 22]. In this approach, both subset selection and MSVM parameter tuning are performed simultaneously which improves the classification performance. This approach is compared with a conventional subset selection in which the subset of features are just selected and the classification parameters do not change.

This paper is structured as follow. First, the considered faults in diode rectifier bridge are studied. Then, discrete wavelet transform and MSVM are discussed. The proposed method for diode rectifier bridge fault detection is represented in the next section. After discussion on the best mother wavelet and order of decomposition, tuned subset selection method is introduced and utilized, for testing proposed method a modified brushless synchronous generator that its rectifier bridge moved from the shaft to the outside machine is used. For classifying faulty and normal conditions of the rectifier bridge. Eventually, a conclusion of the work and best features for detection rectifier bridge diode open circuited faults are compared and represented in the final section.

\section{Studied diode fault types on the rectifier bridge}

Synchronous generators are widely used to generate electrical power all around the world. In this type of machines, the field winding is placed on the rotor and a direct current power supply is required to produce the magnetic field. Supplying the field winding has been carried out in several ways such as external auxiliary DC generators, external auxiliary synchronous generator along with power electronic converters, and supplying the field winding by an external power electronics power supplies using brushes and rings. In the second type synchronous generator, the field supply is provided by another synchronous generator whose armature is placed on the rotor and its $\mathrm{AC}$ output is rectified by a rectifier bridge to provide a direct current. Hence, the rectifier bridge must rotate with the shaft and there is no direct access to it. This type of generator is called brushless synchronous generator. In the brushless synchronous generators, because of the brushes and rings removal, the reliability increases and the need for maintenance diminishes comparing to the other types of synchronous generator. Due to their benefits, they are a suitable choice in sensitive applications, such as submarines or aircraft. The AC output of the auxiliary generator whose field coil is stationary and armature winding rotates with shaft must be rectified to provide the demanded direct current for supplying the main generator field winding. To do so, a rectifier bridge mounted on a plate attached to the shaft rectifies further to the $\mathrm{AC}$ output voltage of the auxiliary generator [23]. Since the direct access to the rectifier bridge is not possible, usually uncontrolled rectifiers (diode) are used for rectifying. Each diode of the rectifier bridge could be open-circuited or short-circuited when it is faced with fault Besides the special case of diode open circuit, open circuited fault could happen as a result of unprotected diode shortcircuited. In this paper, two kinds of fault are studied, in the case of one diode open-circuit, that diode ceases rectifying, and hence open circuit of one of the diodes in the rectifier bridge is considered as the first type of fault. In addition, if one another diode becomes open-circuit beside the opencircuited diode in the same leg of the rectifier bridge that is equal to the loss of one input phase of the rectifier bridge and it defines as the second type of fault. The aim of this research is to propose an approach to be applicable to the brushles synchronous generators in thermal plants. The operation of thermal power plants is such that in order to minimize the operational costs and thermal and mechanical stresses, in star up the generator stay in no-load condition and after a certain period, loading from the generator starts. Due to the fact that thermal power plants are used in the base load, thei generators usually work close to full-load condition [24].

Considering the three states of the rectifier bridge, i.e. healthy, one diode open circuit, and one phase open circuit, the vibration signals of the machine under full-load and noload conditions are recorded. All six possible states of this study are listed in Table 1 below. Since the vibration behavio changes with generator load changes, measurements are made for each state individually. But due to the fact that in case of no load or full load the condition of the rectifier bridge does not change, states 1 and 2, 3 and 4 and 5 and 6 are considere as classes 1,2 and 3 respectively.

\begin{tabular}{|c|c|c|c|}
\hline & & & \\
\hline State & Rectifier Condition & Condition & Label \\
\hline 1 & Healthy & No Load & 1 \\
\hline 2 & Healthy & Full Load & 1 \\
\hline 3 & $\begin{array}{l}\text { One of the six diodes is open } \\
\text { circuited }\end{array}$ & No Load & 2 \\
\hline 4 & $\begin{array}{l}\text { One of the six diodes is open } \\
\text { circuited }\end{array}$ & Full Load & 2 \\
\hline 5 & $\begin{array}{l}\text { A phase (two diodes) of three-phase } \\
\text { connection is open circuited }\end{array}$ & No Load & 3 \\
\hline 6 & $\begin{array}{l}\text { A phase (two diodes) of three-phase } \\
\text { connection is open circuited }\end{array}$ & Full Load & 3 \\
\hline
\end{tabular}

In Fig. 1 electrical rotating components of brushless synchronous generator along with its stator are demonstrated. 


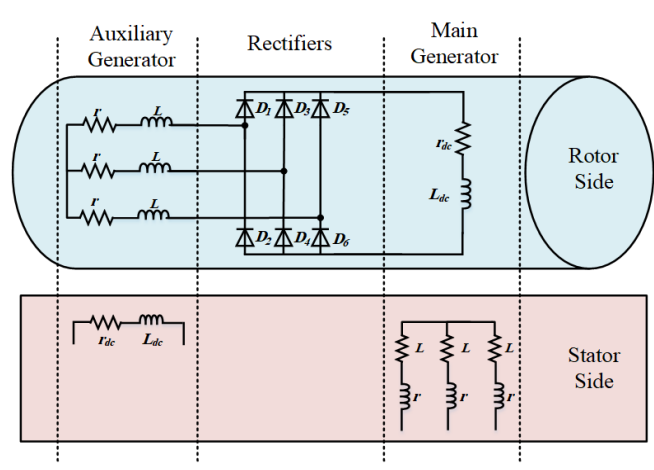

Fig. 1. Electrical components of the brushless synchronous generator.

If the open-circuit fault occurs on diode D1 it can be assumed to be omitted from the circuit and rectifier bridge does not work as a balanced six-pulse rectifier. In the second case, if diodes D1 and D2 become open-circuited it leads to one phase open-circuit. The simulation results in Fig. 2 illustrates the effect of the incurred faults on the voltage and current of the rectifier bridge for various faults in the rectifier bridge. For this purpose, the current and voltage of the rectifier bridge under healthy, one diode, and one phase open-circuit faults are simulated and compared during no load and full loa condition in Fig. 2. As can be seen from this figure, the number of harmonic components in both current and voltage increases by an increase in the number of open-circuit diodes. The incurred changes in the voltage and current of the rectifier bridge lead to further fluctuations of the air gap flux compared to the healthy condition and this, in turn, will result in unwanted changes in the vibration signals measured from the machine.
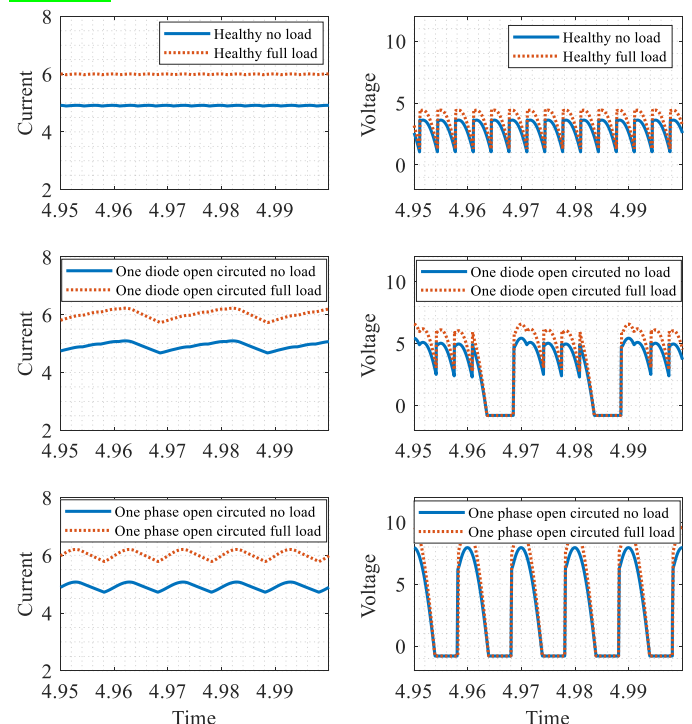

Fig. 2. The simulation results for the rectifier output current and voltage during healthy, one diode open-circuit and one phase open-circuit conditions.

\section{Mathematical background}

\subsection{Wavelet feature extraction}

Signal measurements are usually performed in the time domain. The measured time signals have a lot of information, some of which can be extracted in the time domain. To extract other information in the signal, frequency or time-frequency transformations are usually used. The wavelet transform is one of those transforms. Some articles dealing with fault detection using vibration signals, the wavelet transform is utilized for feature extraction [25-27]. The basis of the wavelet transform is that the input signal is decomposed into some components with different frequency resolutions that are called wavelets [28]. By using a unique mother wavelet $\psi(t)$, the wavelet family $\psi_{a, b}$ is resulted which is scaled by factor $a$ and transformed by factor $b$ of mother wavelet as

$$
\psi_{a, b}=\frac{1}{\sqrt{a}} \psi\left(\frac{t-b}{a}\right)
$$

In (1), $t$ is the time and values of $a$ and $b$ are from $\mathfrak{R}$ domain [29]. In order to use the wavelet transform in performing numerical calculations, the discrete wavelet transform is usually used. For this purpose, $a$ and $b$ are substitute with $a_{j}=2^{j}$ and $b_{j, k}=2^{j} k$. where, $j$ is the scale factor and $k$ is the shift factor. By replacing new variables, the mother wavelet family becomes

$$
\psi_{j, k}=2^{-j / 2} \psi\left(2^{-j} t-k\right)
$$

where $\psi_{j, k}$ is for an orthonormal basis of square integrable space $L^{2}(\Re)[30,31]$. Finally, the discrete wavelet transform of $f(t)$ is defined as

$$
w(j, k)=2^{-j / 2} \int \psi\left(2^{-j} t-k\right) f(t) d t
$$

As shown in Fig. 3, the vibration signal decomposition is carried out up to 4 levels where $A_{1}, \ldots, A_{4}$ are approximation components of the vibration signal and $D_{1}, \ldots, D_{4}$ are its detail components. The waveforms of the original signal, as well as the detail components and the last approximation component, are illustrated in Fig. 3. As can be seen, the signal $F$ can be written as the composition of detail components and the last approximation component. One of the features of the discrete wavelet transform used here for the classification is the relative wavelet energy of the approximation and detail components for each vibration signal. This provides useful information about the vibration signal at different frequency bands.

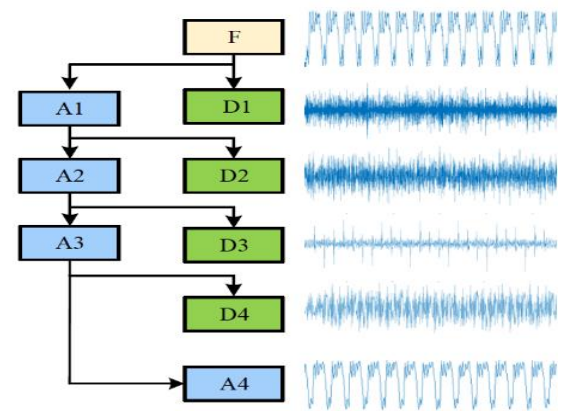

Fig. 3. Level-4 decomposition of discrete input vibration signal $F$. 
Considering level- $N$ decomposition for the input vibration signal, the energy of detail components at each decomposition level is defined according to (4) [30]and the energy of approximation components at level $N$ is defined according to (5).

$$
\begin{aligned}
& E_{D_{j}}=\sum_{k}\left|D_{j}[k]\right|^{2} \quad j=1, \ldots, N \\
& E_{A_{N}}=\sum_{k}\left|A_{N}[k]\right|^{2}
\end{aligned}
$$

To derive relative energy, the total energy of the decomposed vibration signal is needed and it is defined as below.

$$
E_{\text {tot }}=E_{A_{N}}+\sum_{j=1}^{N} E_{D_{j}}
$$

Finally, the relative wavelet energy of decomposition components is defined as

$$
\rho_{\left(\mathrm{D}_{j} \text { or } A_{N}\right)}=\frac{E_{\left(\mathrm{D}_{j} o r A_{N}\right)}}{E_{t o t}} \times 100
$$

\subsection{Multiclass support vector machine}

Support vector machine is a powerful machine learning for two-group classification problems [32]. The SVM classifies data by finding the best hyperplane which separates all data points of one class from the points that belong to the other class in a way that largest margin between the two classes is achieved. In some binary classification problems, the hyperplane is complex for an appropriate separating criterion. For those problems, a mathematical approach can be used to retain almost all the simplicity of an SVM separating hyperplane. The SVM problem is formulated on a set of features $D_{m}$ defined as $D_{m}=\left\{\left(\mathbf{x}_{i}, y_{i}\right) \mid i=1, \ldots, p\right\}$, where the index $m=1, \ldots, q$ refers to the subset number and the index $i$ refers to the number of features for each subset. Here $p$ is the total number of features and $q$ is the total number of subsets on which the SVM method is applied. Moreover, $\mathbf{x}$ refers to the vector of features with the appropriate dimension for each subset $D_{m}$ and $y_{i} \in\{-1,1\}$ is the class label used for training. The subsets $D_{m}$ are defined more explicitly in the next section. Consider the class of nonlinear kernel functions $K\left(\mathbf{x}_{j}, \mathbf{x}_{k}\right)$ as

$$
K\left(\mathbf{x}_{j}, \mathbf{x}_{k}\right)=\varphi\left(\mathbf{x}_{j}\right) \cdot \varphi\left(\mathbf{x}_{k}\right)
$$

where $\varphi$ is a non-linear function which maps the input space to the $N$-dimensional space. Some of these so-called kernel functions and their definitions are introduced in Table 2 [33].

Table 2 kernel function definition.

\begin{tabular}{lc}
\hline \hline Kernel function & Definition \\
\hline Gaussian & $e^{-\left\|\mathbf{x}_{\mathbf{j}}-\mathbf{x}_{k}\right\|^{2}}$ \\
Linear & $\mathbf{x}_{\mathbf{j}}^{\prime} \mathbf{x}_{\mathrm{k}}$ \\
Polynomial & $\left(1+\mathbf{x}_{j}^{\prime} \mathbf{x}_{k}\right)^{q}$ \\
\hline
\end{tabular}

As it was mentioned previously, the SVM is a binary classifier. Therefore, a method must be adapted to be combined with the SVM and make it useful for multiclass applications. In this paper, error-correcting output codes (ECOC) is used that is a classifier for multiclass learning by reduction to binary classifiers [33]. In the ECOC approach with $N$ classes, up to $2^{N-1}-1$ SVMs are trained where each is used to separate a different combination of classes [34]. For classification evaluation, $v$-fold cross-validation is used in which the original data is partitioned into $v$ equal size subsets in which $v$-1 subsets are used for training and one subset is used for evaluation. This process is repeated $v$ times for all subsets. The classifier accuracy is then defined as the fraction of accurately classified observations to all observations. A parameter that may affect the classification accuracy is the box constraint which is a parameter that controls the maximum penalty imposed on margin-violating observations, and aids in preventing overfitting. The box constraint increment leads to the SVM classifier fewer support vector assignment and on the other hand, the longer training times.

For evaluation classification performance, the MSE method for input observations $x_{h}$ is used. According to (9), $y_{h}$ and $t_{h}$ are the number of real class label and the evaluated class for $h^{\text {th }}$ input feature, $l$ is the number of observations, and $g$ is the index for each cross validation.

$$
\operatorname{MSE}\left(x_{h}\right)=\frac{1}{v l} \sum_{g=1}^{v} \sum_{h=1}^{l}\left(y_{h}-t_{h}\right)_{g}^{2}
$$

Due to the fact that the maximum classification accuracy is 1 , the classification accuracy is defined as follows $\operatorname{Accuracy}\left(x_{h}\right)=1-\operatorname{MSE}\left(x_{h}\right)$

\section{The proposed fault detection approach}

In order to detect faults occurring on the rectifier bridge of the brushless synchronous machine, the vibration signal of the machine is recorded under the faulty and healthy conditions. Fig. 4 shows a diagram for the proposed algorithm by dividing it into three subsections. In the first step which is called preprocessing, all vibration signals are measured, standardized and outliers are neglected. The data segmentation is also performed at this stage. As the next step feature extraction is performed, and the classification performance is evaluated for different mother wavelet and decomposition level. Beside of wavelet features, ten statistical features including mean, mean of absolute value, root mean square (RMS), standard deviation, variance, skewness, kurtosis, impulse factor, crest factor, and energy are calculated and added (see Table 3). Note that using more features may decrease classifier speed and may lead to overfitting of the classifier. Therefore, the optimum set of features are selected in the last step using the forward subset selection method. For this purpose, the forward subset selection method is modified by searching for different classifier kernel functions and box constraints in the search areas for each epoch.

The subset selection technique is explained by defining the statistical features of the vibration signal as

$$
F_{1}=\left\{f_{1}^{1}, f_{2}^{1}, \ldots, f_{i}^{1}, \ldots, f_{n}^{1}\right\}
$$

where each element in $F_{1}$ set is one statistical feature and $n$ is the number of statistical features. In this notation, $f_{i}^{j}$ means $i^{\text {th }}$ statistical feature of set $F_{1}$ and the superscript $j$ indicated the reordering number. The best wavelet features are written as

$$
W=\left\{w_{1}, w_{2} \ldots, w_{m}\right\}
$$

where $w_{1}$ is the approximation component and others are detailed components. Here the subscript $m$ is equal to the decomposition level plus one. Here $S_{i}$ defines different subsets and it is null at the beginning. As the first step of forward 
subset selection, the statistical features are chosen from set $F_{1}$ one by one and put next to the wavelet features to form the first order subset $\mathrm{S}_{1}$.

$$
S_{1}=\left\{\left\{W, f_{1}^{1}\right\},\left\{W, f_{2}^{1}\right\}, \ldots,\left\{W, f_{i}^{1}\right\}, \ldots,\left\{W, f_{n}^{1}\right\}\right\}
$$

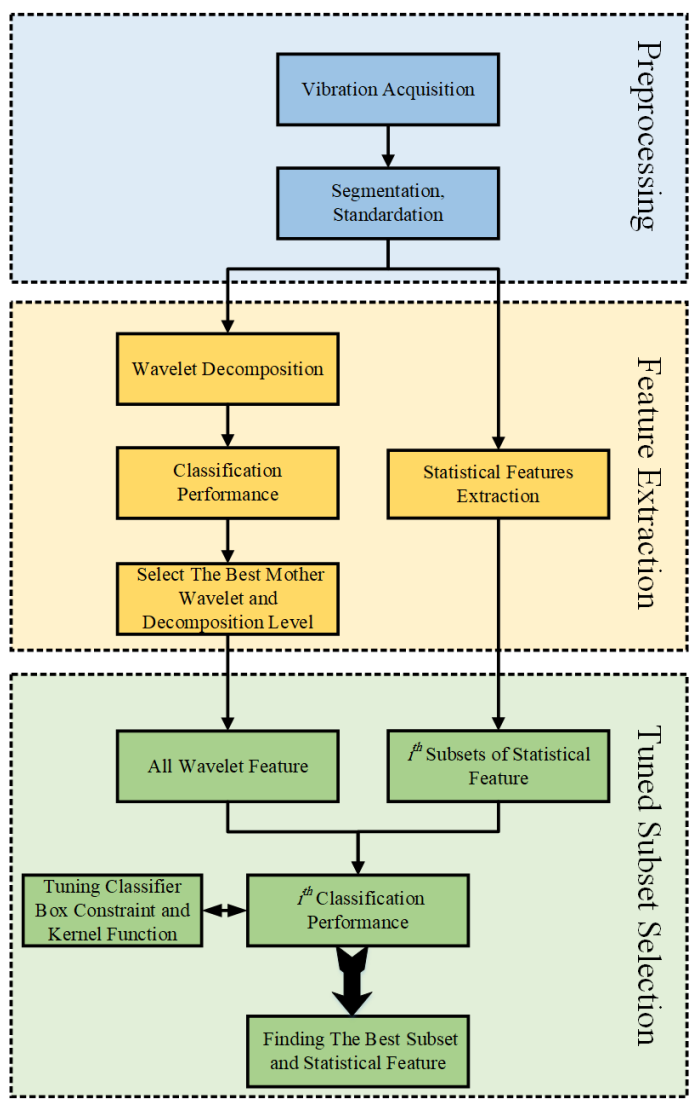

Fig. 4. The flowchart of the proposed fault detection method.

Considering (10), the accuracy of classification for each element of $S_{1}$, is evaluated for different box constraint and kernel function in the search area. In this way, the best statistical feature $f_{1}^{*}=f_{i}^{1}$ and the best performance for the first order subsets $S_{1}$, are calculated according to (14).

$f_{1}^{*}=\arg \max \left\{\operatorname{Accuracy}\left(\left\{W, f_{1}^{1}\right\}\right), \ldots\right.$

, Accuracy $\left.\left(\left\{W, f_{n}^{1}\right\}\right)\right\}$

$\max _{1}=\max \left\{\operatorname{Accuracy}\left(\left\{W, f_{1}^{1}\right\}\right), \ldots\right.$

, Accuracy $\left.\left(\left\{W, f_{n}^{1}\right\}\right)\right\}$

Before going to the next step, it is necessary to delete $f_{1}^{*}$ from the set $F_{1}$ and define the set $F_{2}$ as $F_{2}=F_{1}-\left\{f_{1}^{1}\right\}=\left\{f_{1}^{2}, f_{2}^{2}, \ldots, f_{i}^{2}, \ldots, f_{n-1}^{2}\right\}$

By repeating the procedure successively, at step $n$ all $n-1$ previously found statistical features are added to set $S_{n}$ and the search is to find the best $f_{1}^{n}$.

$S_{n}=\left\{\left\{W, f_{1}^{*}, f_{2}^{*}, \ldots, f_{1}^{n}\right\}\right\}$

$f_{n}^{*}=\arg \max \left\{W, f_{1}^{*}, f_{2}^{*}, \ldots, f_{1}^{n}\right\}$

$\max _{n}=\max \left\{\operatorname{Accuracy}\left(W, f_{1}^{*}, f_{2}^{*}, \ldots, f_{1}^{n}\right)\right\}$
Finally, the best subset of features and the classifier performance are found according to (20) and (21) the best subset and features based on classifier performance are calculated.

$$
\begin{aligned}
& \operatorname{argmax}\left\{\max _{1}, \max _{2}, \ldots, \max _{n}\right\} \\
& \max _{\operatorname{lax}}\left\{\max _{1}, \max _{2}, \ldots, \max _{n}\right\}
\end{aligned}
$$

Table 3

\begin{tabular}{llc}
\multicolumn{3}{c}{ Statistical features definition. } \\
\hline $\begin{array}{l}\text { Item } \\
\text { Number }\end{array}$ & $\begin{array}{l}\text { Statistical } \\
\text { Feature } \\
\text { Name }\end{array}$ & Definition \\
\hline 1 & Mean & $\frac{1}{N} \sum_{i=1}^{N} x_{i}$ \\
2 & $\begin{array}{l}\text { Mean of } \\
\text { Absolute }\end{array}$ & $\frac{1}{N} \sum_{i=1}^{N}\left|x_{i}\right|$ \\
3 & RMS & $\sqrt{\frac{1}{N} \sum_{i=1}^{N} x_{i}^{2}}$ \\
4 & $\begin{array}{l}\text { Standard } \\
\text { Deviation }\end{array}$ & $\sqrt{\frac{1}{N-1} \sum_{i=1}^{N}\left(x_{i}-\bar{x}\right)^{2}}$ \\
5 & Variance & $\frac{1}{N-1} \sum_{i=1}^{N}\left(x_{i}-\bar{x}\right)^{2}$ \\
6 & Skewness & $\frac{1}{N} \sum_{i=1}^{N} \frac{\left(x_{i}-\bar{x}\right)^{3}}{\sigma^{3}}$ \\
7 & Kurtosis & $\frac{1}{N} \sum_{i=1}^{N} \frac{\left(x_{i}-\bar{x}\right)^{4}}{\sigma^{4}}$ \\
8 & Impulse & $\frac{\sqrt{\frac{1}{N} \sum_{i=1}^{N} x_{i}^{2}}}{\frac{1}{N} \sum_{i=1}^{N}\left|x_{i}\right|}$ \\
& Factor & $\frac{\max \left|x_{i}\right|}{\sqrt{\frac{1}{N} \sum_{i=1}^{N} x_{i}^{2}}}$ \\
9 & Crest Factor & $\sum_{i=1}^{N} x_{i}^{2}$ \\
10 & Energy & \\
\hline & &
\end{tabular}

\section{Test rig and data acquisition}

In order to apply the proposed fault detection and classification in the rectifier bridge, the laboratory setup shown in Fig. 5 is built. As can be seen in Fig. , the setup is made of the following components: the modified three-phase $380 \mathrm{~V}, 11 \mathrm{kVA}, 4$ poles brushless synchronous generator with rectifier bridge and switch set for applying faults, the induction motor for driving the generator, the DC supply as a direct current source for the auxiliary generator field winding, the 3-phase electric load, electrical drive for rotating motor and generator at synchronous speed and vibration measurement instruments. The used vibration measurement set is Easy-Viber ${ }^{\circledR}$ model of VMI company and the vibration sensor is an accelerometer. The sampling frequency chosen for data acquisition is $8192 \mathrm{~Hz}$

To apply faults to the rectifier bridge, brushless synchronous generator is modified and a diode rectifier bridge is installed outside of the machine along with a set of switches. The three-phase output of the auxiliary synchronous generator and the field winding of the main generator located on the rotor, are connected to the rectifier bridge through the embedded brushes and rings as shown in Fig. . When each switch becomes off, the corresponding diode becomes opencircuit and in this way, the intended faults can be applied and 
vibration measurements of the generator during faulty and normal condition are measured. The vibration of the machine is recorded in six states as it is listed in Table 1, i.e. healthy performance, one diode open-circuit fault, and two diode open-circuit fault under full-load and no-load conditions of the machine for each mentioned state. The recorded timedomain vibration signals for the period of 0.4 second and different fault conditions are plotted in Fig. 6 to Fig. 11.

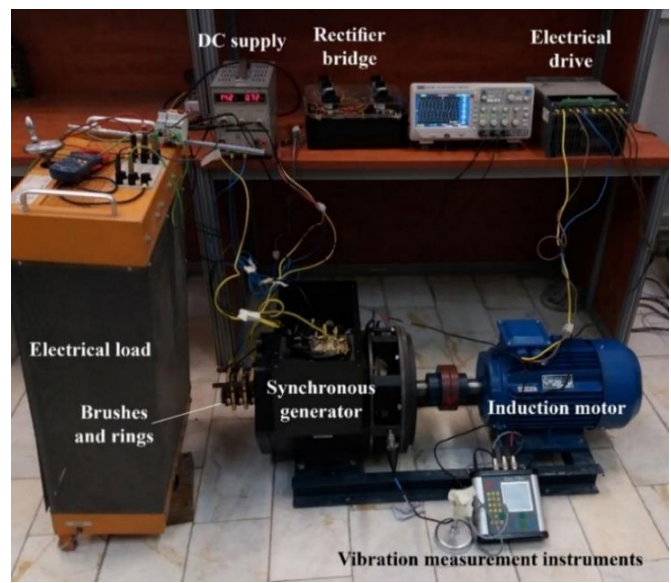

Fig. 5. Test rig designed for data acquisition.

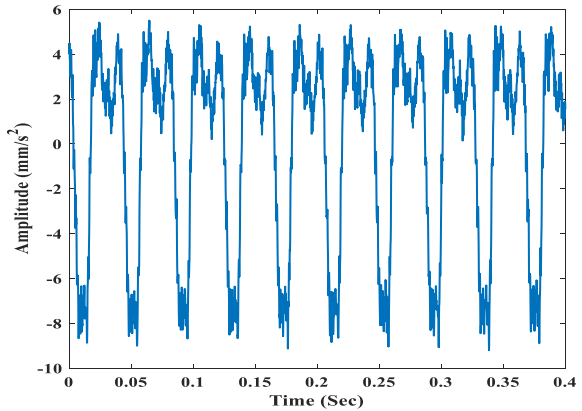

Fig. 6. Time domain vibration signals of the synchronous machine in the state of healthy and no-load condition of the machine.

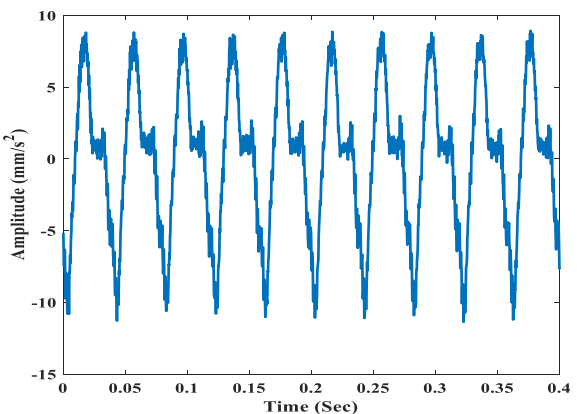

Fig. 7. Time domain vibration signals of the synchronous machine in the state healthy and full-load condition of the machine.

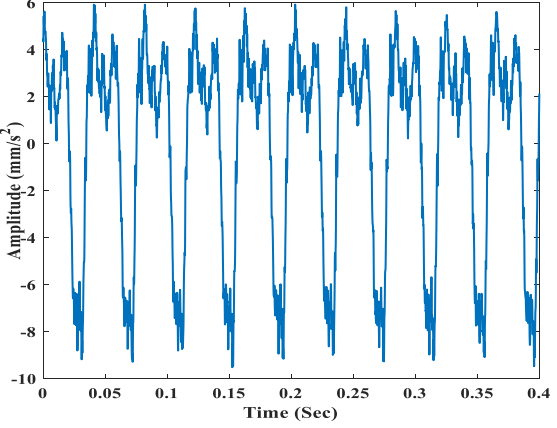

Fig. 8. Vibration signals in the state of one diode opencircuit and no-load condition of the machine.

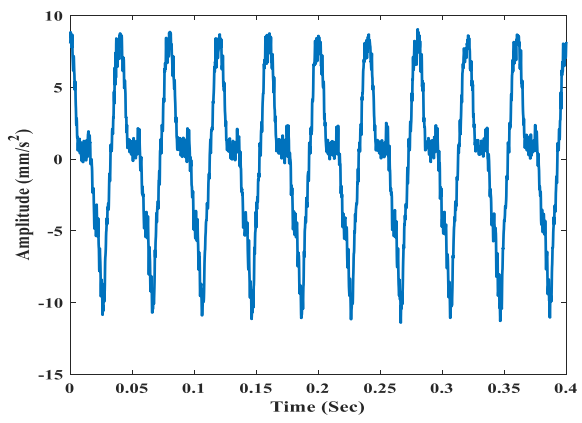

Fig. 9. Vibration signals in the state of one diode opencircuit and full-load condition of the machine.

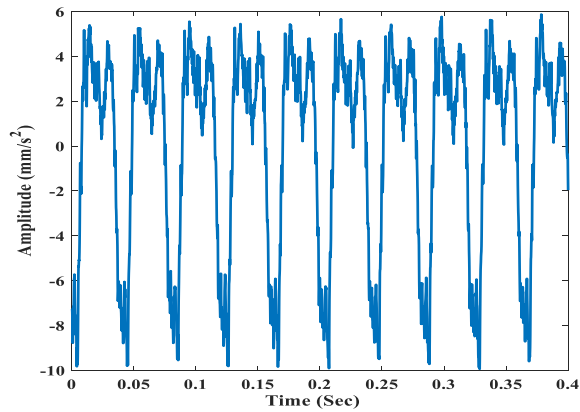

Fig. 10. Vibration signals in the state of two diodes opencircuit and no-load condition of the machine.

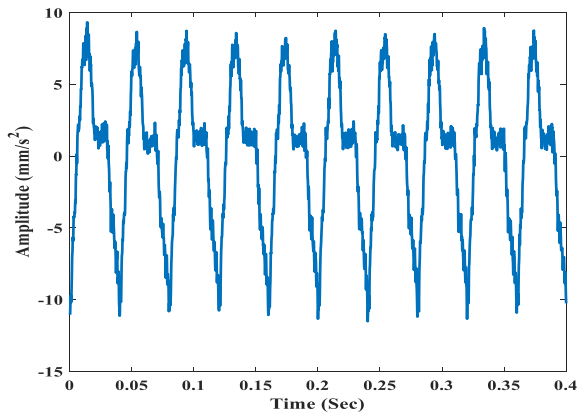

Fig. 11. Vibration signals in the state of two diodes opencircuit and full-load condition of the machine. 


\section{Selecting Mother Wavelet and Decomposition level}

The vibration signals are recorded for twenty-one second for each state for classification purpose. The relative wavelet energy for each sample is then calculated, and they are used for classification using MSVM and 5-fold crossvalidation is explained in section 3.2 . Looking at the available literature, various mother wavelets are applied for faul detection using vibration signals. For example, in [35-39] Daubechies wavelet, in [40, 41] Haar wavelet, in [42] Coifle wavelet, and in [43] discrete Meyer wavelet are employed fo fault detection using vibration signals. Moreover, wavelets are also used to detect faults in electrical rotating machines using an electrical signal. For example, in [39] Daubechies is used for inter-turn fault detection of induction machines, and Haar wavelet is utilized in [40], for detection of short circuits in induction motor winding. Considering this review, five mother wavelets reported in [44] as well as Fejer Korovkin are employed to investigate the influence of different mother wavelets on the rectifier bridge fault detection using vibration signal. The results in Figs. 12 to 17 show the effect of differen mother wavelets and decomposition levels on the classification accuracy of the fault. For each wavelet, the classification algorithm is executed for 30 decomposition levels, and the decomposition level corresponding to the maximum classification accuracy is chosen. Finally, the bes maximum accuracy for different wavelets indicates the bes wavelet for this application. Considering Figs. 12 to 17, the maximum classification accuracy of $77 \%$ is achieved by the Symlet mother wavelet and level-6 decomposition. Therefore, the Symlet mother wavelet and level-6 decomposition are chosen for the rest of the work.

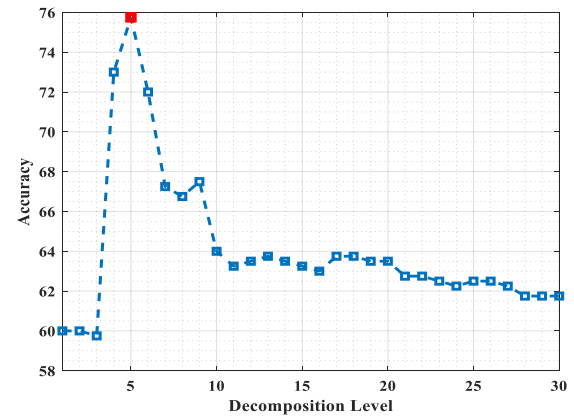

Fig. 12. Classification accuracy with respect to decomposition level using Daubechies mother wavelet.

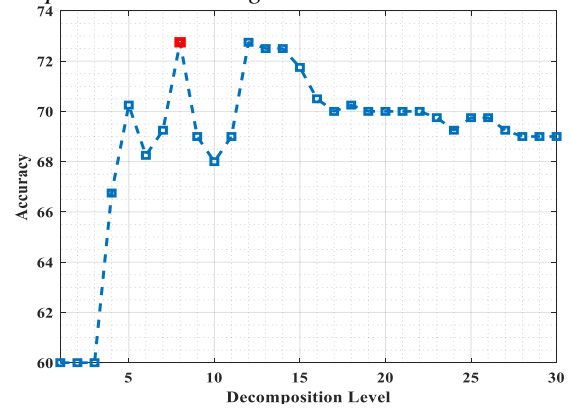

Fig. 13. Classification accuracy with respect to decomposition level using Coiflet mother wavelet.

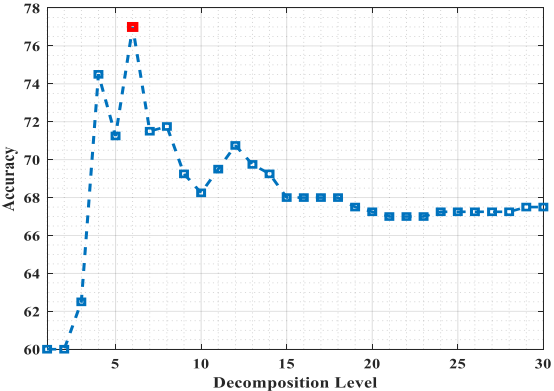

Fig. 14. Classification accuracy with respect to decomposition level using Symlet mother wavelet.

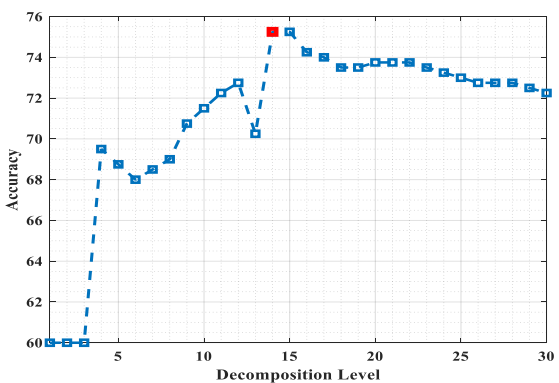

Fig. 15. Classification accuracy with respect to decomposition level using Haar mother wavelet.

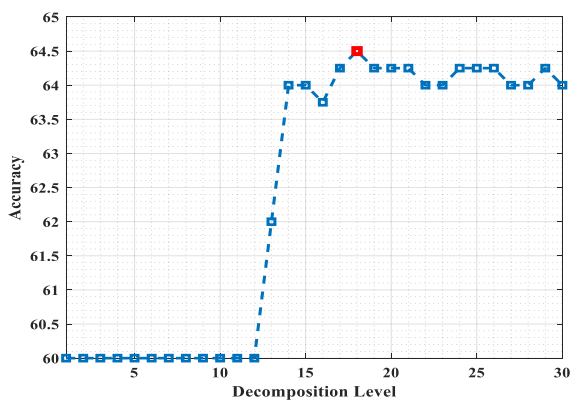

Fig. 16. Classification accuracy with respect to decomposition level using discrete Meyer mother wavelet.

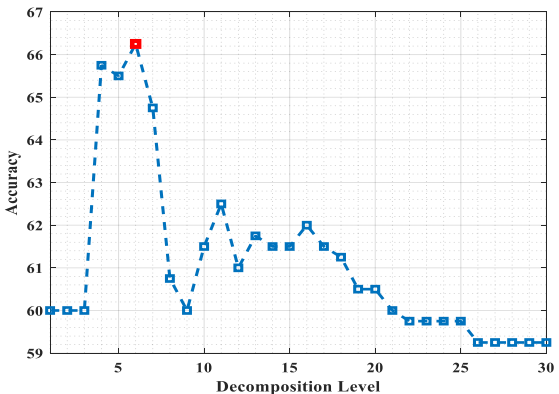

Fig. 17. Classification accuracy with respect to decomposition level using Fejer Korovkin mother wavelet. 


\section{Classification Performance of whole proposed approach}

The aim of this investigation is to use statistical features along with wavelet features to improve classification performance. On the one hand, the maximum classification accuracy using only wavelet features is $77 \%$ as shown in section 6. On the other hand, it is not clear adding which statistical feature will enhance the classification performance. Therefore, a subset selection approach is employed to choose the appropriate set of features. In Table 4, the results of the conventional subset selection are presented where $S_{\mathrm{i}}$ is subset $i$ as explained in section 4 . The index $i$ here refers to the number of the statistical feature in each subset and the item number used in Table 3 represents the name of the selected statistical feature and SW refers to Symlet Wavelet. In the first step of this approach, feature 7 (Kurtosis) is selected for $S_{l}$ as it leads to the highest classification accuracy (about78\%). In the next step, feature 3 (RMS) is selected to use besides Symlet wavelet and feature 7 as they result in the best classification performance amongst the other 9 remaining features. This procedure is repeated for 10 steps and 10 subsets $\left(S_{1}, \ldots, S_{10}\right)$ with 1 to 10 additional statistical features are created. At the end of the procedure, the subset $S_{5}$, as shown in Table 4, is selected for the highest possible accuracy of $84.75 \%$.

Table 4 Forward Subset Selection

\begin{tabular}{lll}
\hline \hline Names & Features & Accuracy \\
\hline $\mathrm{S}_{1}$ & $\mathrm{SW}, 7$ & 78.25 \\
$\mathrm{~S}_{2}$ & $\mathrm{SW}, 7,3$ & 78.75 \\
$\mathrm{~S}_{3}$ & $\mathrm{SW}, 7,3,2$ & 82.5 \\
$\mathrm{~S}_{4}$ & $\mathrm{SW}, 7,3,2,6$ & 84.25 \\
$\mathrm{~S}_{5}$ & $\mathbf{S W}, \mathbf{7 , 3 , 2 , 6 , 4}$ & $\mathbf{8 4 . 7 5}$ \\
$\mathrm{S}_{6}$ & $\mathrm{SW}, 7,3,2,6,4,8$ & 84.5 \\
$\mathrm{~S}_{7}$ & $\mathrm{SW}, 7,3,2,6,4,8,5$ & 84.25 \\
$\mathrm{~S}_{8}$ & $\mathrm{SW}, 7,3,2,6,4,8,5,10$ & 84.25 \\
$\mathrm{~S}_{9}$ & $\mathrm{SW}, 7,3,2,6,4,8,5,10,9$ & 83.75 \\
$\mathrm{~S}_{10}$ & $\mathrm{SW}, 7,3,2,6,4,8,5,10,9,1$ & 83 \\
\hline
\end{tabular}

In the conventional subset selection, the classification parameters are left unchanged while they may influence the classification accuracy and the selected subset. For instance, by using the proposed method, the classification accuracy for different kernel functions and different box constraint values using one statistical feature besides Symlet wavelet is presented in Fig. 18 to Fig. 27. According to these figures, the highest accuracy, $88.75 \%$ is achieved by using the mean of absolute, the Gaussian kernel, and the box constraints either 1 or2. However, using the conventional subset selection, the highest accuracy achieved by Kurtosis is about $78 \%$ (using linear kernel and box constraint 1). For other statistical features, the influence of the kernel function and box constraint is also significant. For example, according to Fig.25, the maximum classification accuracy for the impulse factor using Gaussian kernel and box constraint 1 is $81.25 \%$, while the other choices for classification parameters lead to the classification accuracy of lower than $80 \%$. Obviously, to achieve the best possible performance the kernel function and box constraint must be considered in subset selection. Therefore, in the proposed subset selection approach, for each statistical feature, the classification parameters are considered in the algorithm to be tuned.

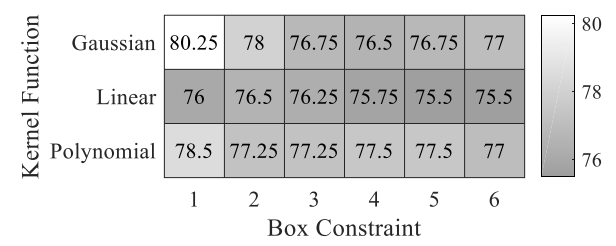

Fig.18. Accuracy for kernel functions Gaussian, Linear, and Polynomial using Symlet wavelet along with average feature.

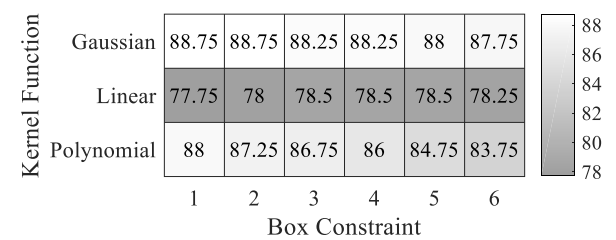

Fig. 19. Accuracy for kernel functions Gaussian, Linear, and Polynomial using Symlet wavelet along with mean of absolute feature.

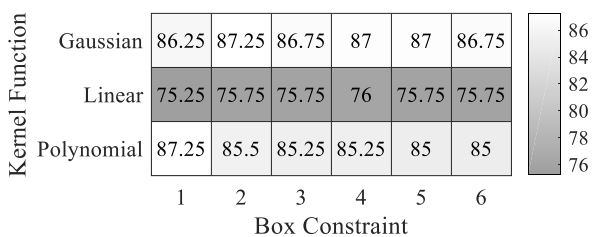

Fig. 20. Accuracy for kernel functions Gaussian, Linear, and Polynomial using Symlet wavelet along with RMS feature.

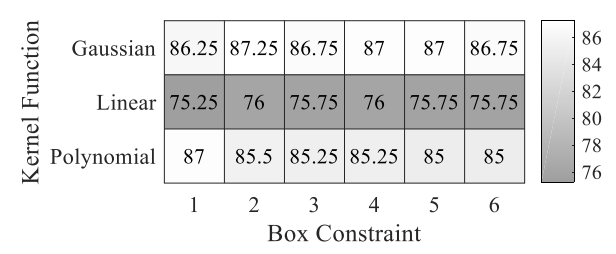

Fig. 21. Accuracy for kernel functions Gaussian, Linear, and Polynomial using Symlet wavelet along with standard deviation feature.

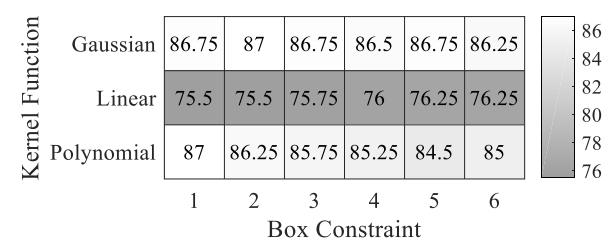

Fig. 22. Accuracy for kernel functions Gaussian, Linear, and Polynomial using Symlet wavelet along with variance feature. 


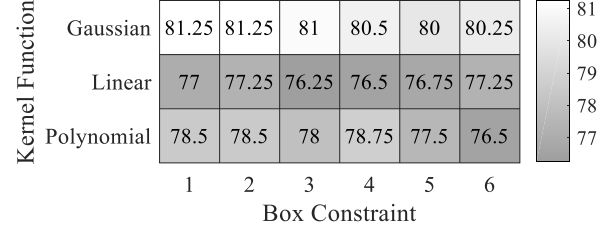

Fig. 23. Accuracy for kernel functions Gaussian, Linear, and Polynomial using Symlet wavelet along with skewness feature.

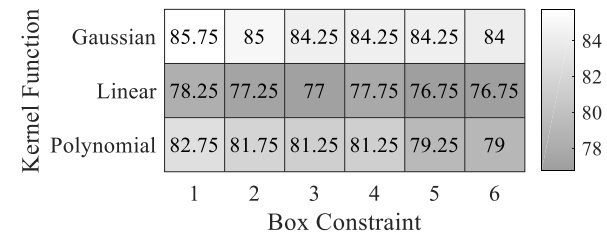

Fig. 24. Accuracy for kernel functions Gaussian, Linear, and Polynomial using Symlet wavelet along with kurtosis feature.

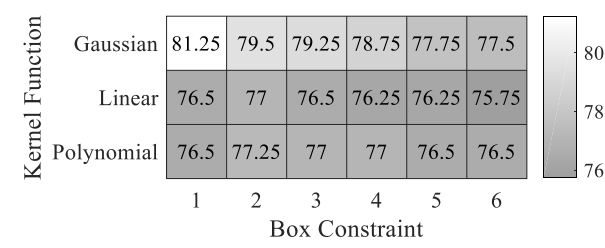

Fig. 25. Accuracy for kernel functions Gaussian, Linear, and Polynomial using Symlet wavelet along with impulse factor feature.

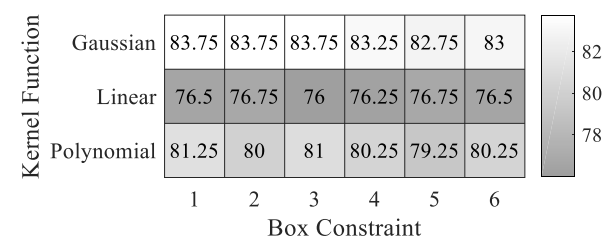

Fig. 26. Accuracy for kernel functions Gaussian, Linear, and Polynomial using Symlet wavelet along with crest factor feature.

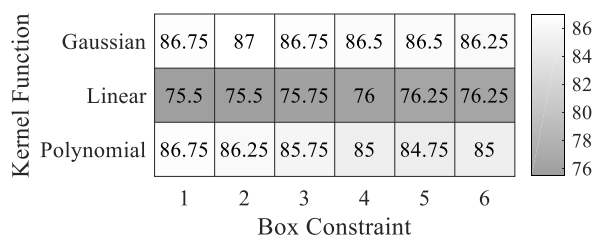

Fig. 27. Accuracy for kernel functions Gaussian, Linear, and Polynomial using Symlet wavelet along with energy feature.

This is investigated further in Tables 5 to 14 , by listing the classification accuracy for each statistical feature using the subsets $\left(S_{1}, \ldots, S_{10}\right)$. In each case, the kernel functions and the box constraints are tuned to achieve the highest classification accuracy for the corresponding features. For example, in the first step of the proposed approach, the algorithm selects mean of absolute as the best first statistical feature while the chosen kernel function and box constraint for this feature by the algorithm is Gaussian and 1 respectively. Considering the lower training time, it is desired to have less value for the box constraint for equal accuracy. Therefore, according to Fig. 19, the box constraint 1 is chosen for the classification accuracy of $88.75 \%$ after choosing the kernel and box constraint for maximum accuracy. However, according to Table 5, the algorithm employs only box constraint 1 . This procedure is repeated for all other features and all other steps. After selecting a suitable statistical feature in the first step, nine other statistical features are employed for subset selection and used along with the wavelet feature in the next step.

Table 5 Tuned Forward $1^{\text {st }}$ Subset Selection.

\begin{tabular}{cccc}
\hline \hline Features & $\begin{array}{c}\text { Kernel } \\
\text { function }\end{array}$ & $\begin{array}{c}\text { Box } \\
\text { Constraint }\end{array}$ & Accuracy \\
\hline SW,1 & Gaussian & 1 & 80.25 \\
SW,2 & Gaussian & $\mathbf{1}$ & $\mathbf{8 8 . 7 5}$ \\
SW,3 & Gaussian & 2 & 87.25 \\
SW,4 & Gaussian & 2 & 87.25 \\
SW,5 & Polynomial & 1 & 87 \\
SW,6 & Gaussian & 1 & 81.25 \\
SW,7 & Gaussian & 1 & 85.75 \\
SW,8 & Gaussian & 1 & 81.25 \\
SW,9 & Gaussian & 1 & 83.75 \\
SW,10 & Gaussian & 2 & 87 \\
\hline
\end{tabular}

Table 6 Tuned Forward $2^{\text {nd }}$ Subset Selection.

\begin{tabular}{cccc}
\hline \hline Features & $\begin{array}{c}\text { Kernel } \\
\text { function }\end{array}$ & $\begin{array}{c}\text { Box } \\
\text { Constraint }\end{array}$ & Accuracy \\
\hline SW,2,1 & Gaussian & 4 & 89.5 \\
SW,2,3 & Polynomial & 1 & 89.5 \\
SW,2,4 & Polynomial & 1 & 89.5 \\
SW,2,5 & Polynomial & 1 & 89.75 \\
SW,2,6 & Gaussian & 1 & 89.75 \\
SW,2,7 & Gaussian & $\mathbf{2}$ & $\mathbf{9 1 . 2 5}$ \\
SW,2,8 & Gaussian & 2 & 88 \\
SW,2,9 & Gaussian & 1 & 90 \\
SW,2,10 & Polynomial & 1 & 89.75 \\
\hline
\end{tabular}

Table 7 Tuned Forward $3^{\text {rd }}$ Subset Selection.

\begin{tabular}{cccc}
\hline \hline Features & $\begin{array}{c}\text { Kernel } \\
\text { function }\end{array}$ & $\begin{array}{c}\text { Box } \\
\text { Constraint }\end{array}$ & Accuracy \\
\hline SW,2,7,1 & Gaussian & $\mathbf{6}$ & $\mathbf{9 1 . 7 5}$ \\
SW,2,7,3 & Gaussian & 2 & 91.5 \\
SW,2,7,4 & Gaussian & 2 & 91.5 \\
SW,2,7,5 & Gaussian & 2 & 91.5 \\
SW,2,7,6 & Gaussian & 2 & 91.25 \\
SW,2,7,8 & Gaussian & 2 & 90.5 \\
SW,2,7,9 & Gaussian & 4 & 91.25 \\
SW,2,7,10 & Gaussian & 2 & 91.5 \\
\hline
\end{tabular}


Table 8 Tuned Forward $4^{\text {th }}$ Subset Selection.

\begin{tabular}{cccc}
\hline \hline Features & $\begin{array}{c}\text { Kernel } \\
\text { function }\end{array}$ & $\begin{array}{c}\text { Box } \\
\text { Constraint }\end{array}$ & Accuracy \\
\hline SW,2,7,1,3 & Gaussian & $\mathbf{6}$ & $\mathbf{9 2 . 5}$ \\
SW,2,7,1,4 & Gaussian & 6 & 91.75 \\
SW,2,7,1,5 & Gaussian & 6 & 91.5 \\
SW,2,7,1,6 & Gaussian & 2 & 92.25 \\
SW,2,7,1,8 & Gaussian & 3 & 90.75 \\
SW,2,7,1,9 & Gaussian & 4 & 91.75 \\
SW,2,7,1,10 & Gaussian & 6 & 92.25 \\
\hline
\end{tabular}

Table 9 Tuned Forward $5^{\text {th }}$ Subset Selection.

\begin{tabular}{cccc}
\hline \hline Features & $\begin{array}{c}\text { Kernel } \\
\text { function }\end{array}$ & $\begin{array}{c}\text { Box } \\
\text { Constraint }\end{array}$ & Accuracy \\
\hline SW,2,7,1,3,4 & Gaussian & 2 & 92.5 \\
SW,2,7,1,3,5 & Gaussian & 2 & 92.5 \\
SW,2,7,1,3,6 & Gaussian & $\mathbf{2}$ & $\mathbf{9 2 . 7 5}$ \\
SW,2,7,1,3,8 & Gaussian & 3 & 91.5 \\
SW,2,7,1,3,9 & Gaussian & 2 & 92.5 \\
SW,2,7,1,3,10 & Gaussian & 2 & 92.5 \\
\hline
\end{tabular}

Table 10 Tuned Forward $6^{\text {th }}$ Subset Selection.

\begin{tabular}{cccc}
\hline \hline Features & $\begin{array}{c}\text { Kernel } \\
\text { function }\end{array}$ & $\begin{array}{c}\text { Box } \\
\text { Constraint }\end{array}$ & Accuracy \\
\hline SW,2,7,1,3,6,4 & Gaussian & $\mathbf{2}$ & $\mathbf{9 2 . 7 5}$ \\
SW,2,7,1,3,6,5 & Gaussian & 2 & 92.5 \\
SW,2,7,1,3,6,8 & Gaussian & 6 & 92.25 \\
SW,2,7,1,3,6,9 & Gaussian & 3 & 92.5 \\
SW,2,7,1,3,6,10 & Gaussian & 2 & 92.5 \\
& & &
\end{tabular}

Table 11 Tuned Forward $7^{\text {th }}$ Subset Selection.

\begin{tabular}{cccc}
\hline \hline Features & $\begin{array}{c}\text { Kernel } \\
\text { function }\end{array}$ & $\begin{array}{c}\text { Box } \\
\text { Constraint }\end{array}$ & Accuracy \\
\hline SW,2,7,1,3,6,4,5 & Gaussian & $\mathbf{2}$ & $\mathbf{9 2 . 5}$ \\
SW, $2,7,1,3,6,4,8$ & Gaussian & 2 & 92 \\
SW, $2,7,1,3,6,4,9$ & Gaussian & 2 & 92 \\
SW,2,7,1,3,6,4,10 & Gaussian & 2 & 92.25 \\
\hline
\end{tabular}

Table 12 Tuned Forward $8^{\text {th }}$ Subset Selection.

\begin{tabular}{cccc}
\hline \hline Features & $\begin{array}{c}\text { Kernel } \\
\text { function }\end{array}$ & $\begin{array}{c}\text { Box } \\
\text { Constraint }\end{array}$ & Accuracy \\
\hline SW,2,7,1,3,6,4,5,8 & Gaussian & 2 & 91.75 \\
SW,2,7,1,3,6,4,5,9 & Gaussian & $\mathbf{1}$ & $\mathbf{9 2 . 5}$ \\
SW,2,7,1,3,6,4,5,10 & Gaussian & 2 & 92.25
\end{tabular}

Table 13 Tuned Forward $9^{\text {th }}$ Subset Selection

\begin{tabular}{cccc}
\hline \hline Features & $\begin{array}{c}\text { Kernel } \\
\text { function }\end{array}$ & $\begin{array}{c}\text { Box } \\
\text { Constraint }\end{array}$ & Accuracy \\
\hline SW,2,7,1,3,6,4,5,9,8 & Gaussian & 2 & 91.5 \\
$\mathbf{S W , 2 , 7 , 1 , 3 , 6 , 4 , 5 , 9 , 1 0}$ & Gaussian & $\mathbf{1}$ & $\mathbf{9 2 . 7 5}$ \\
\hline
\end{tabular}

Table 14 Tuned Forward $10^{\text {th }}$ Subset Selection.

\begin{tabular}{cccc}
\hline Features & $\begin{array}{c}\text { Kernel } \\
\text { function }\end{array}$ & $\begin{array}{c}\text { Box } \\
\text { Constraint }\end{array}$ & Accuracy \\
\hline $\mathbf{S W , 2 , 7 , 1 , 3 , 6 , 4 , 5 , 9 , 1 0 , 8}$ & Gaussian & $\mathbf{1}$ & $\mathbf{9 1 . 7 5}$ \\
\hline
\end{tabular}

This approach runs until no statistical feature remains and therefore, in the last step all ten statistical features are used along with the wavelet feature (Table 14). The best classification performance for each step of subset selection is plotted in Fig. 28 for both conventional subset selection and the proposed method.

According to Fig. 28, the proposed subset selection selects S5 obtained from step 5 of subset selection which is Symlet wavelet with features $2,7,1,3,6$; the selected box constraint is 2 and the selected kernel function is Gaussian kernel. The classification accuracy achieved using the proposed subset selection is 92.75 while it is $84.75 \%$ using the conventional subset selection. It is obvious from Fig. 28 that the classification performance is significantly enhanced using the proposed approach compared with the conventional method.

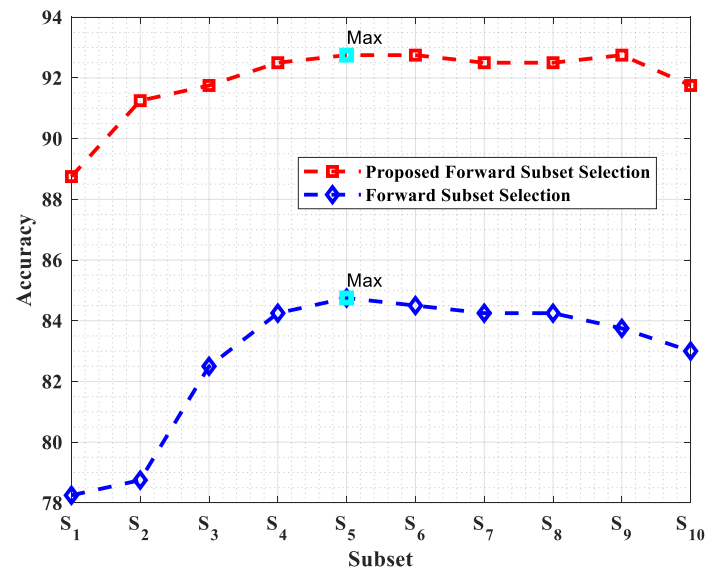

Fig. 28. The classification accuracy against the obtained subsets in each level of the proposed subset selection and the conventional subset selection.

\section{Conclusion}

This paper deals with the rectifier fault detection in the brushless synchronous machines using vibration signals. The vibration signals are measured from the machine's frame for three states of the machine, healthy state, one diode opencircuit, and two diodes open-circuit from the same arm of a three-phase rectifier. For the fault detection of the rectifier, an improved approach using MSVM, discrete wavelet transformation, statistical feature, and a modified forward subset selection is proposed in this paper. At the first performance of classification is compared to find the best mother wavelet and the best decomposition level, using discrete wavelet transformation, the wavelet features are extracted from vibration signals; also, employing MSVM the mother wavelet and the decomposition level of the discrete wavelet transformation, the maximum obtained classification accuracy is about $77 \%$. In order to enhance the classification accuracy of fault detection, statistical features are considered 
to be added to the wavelet features. To find out which features are appropriate for improving classification accuracy the forward subset selection can be employed. However, using the conventional forward subset selection in which only be the best subset of statistical features are selected, the classification accuracy is obtained about $85 \%$. Therefore, an improved model of the forward subset selection is proposed. In the proposed approach, along with statistical features subset selection, the classification parameters are tuned. Consequently, the algorithm selects the subset of features includes Symlet wavelet feature and five statistical features mean of absolute, Kurtosis, mean, RMS, and skewness; and chooses the Gaussian kernel and box constraint 2. By this approach, the classification accuracy of about $93 \%$ is achieved.

\section{References}

[1] Li, R., Li, C., Peng, X., et al.: 'Electromagnetic Vibration Simulation of a 250-MW Large Hydropower Generator with Rotor Eccentricity and Rotor Deformation'Energies, 2017, 10, (12), p. 2155.

[2] Glowacz, A., Glowacz, Z.: 'Diagnosis of stator faults of the single-phase induction motor using acoustic signals'Appl. Acoust., 2017, 117, pp. 20-27.

[3] Ferrando Chacon, J.L., Artigao Andicoberry, E., Kappatos, V., Asfis, G., Gan, T.H., Balachandran, W.: 'Shaft angular misalignment detection using acoustic emission'Appl. Acoust., 2014, 85, pp. 12-22.

[4] Ferrando Chacon, J.L., Kappatos, V., Balachandran, W., Gan, T.-H.: 'A novel approach for incipient defect detection in rolling bearings using acoustic emission technique'Appl. Acoust., 2015, 89, pp. 88100 .

[5] Vaimann, T., Sobra, J., Anouar, B., Rassõlkin, A., Rolak, M., Kallaste, A.: 'Induction machine fault detection using smartphone recorded audible noise'IET Sci. Meas. Technol. , 2018, 12, (4), pp. 554-560.

[6] Ben Ali, J., Fnaiech, N., Saidi, L., Chebel-Morello, B., Fnaiech, F.: 'Application of empirical mode decomposition and artificial neural network for automatic bearing fault diagnosis based on vibration signals'Appl. Acoust., 2015, 89, pp. 16-27.

[7] Zhou, L., Duan, F., Corsar, M., Elasha, F., Mba, D.: 'A study on helicopter main gearbox planetary bearing fault diagnosis'Appl. Acoust., 2017.

[8] Dubey, R., Agrawal, D.: 'Bearing fault classification using ANN-based Hilbert footprint analysis' IET Sci. Meas. Technol., 2015.

[9] Zhou, H., Hong, K., Huang, H., Zhou, J.: 'Transformer winding fault detection by vibration analysis methods'Appl. Acoust., 2016, 114, pp. 136146.

[10] Moosavian, A., Najafi, G., Ghobadian, B., Mirsalim, M., Jafari, S.M., Sharghi, P.: 'Piston scuffing fault and its identification in an IC engine by vibration analysis'Appl. Acoust., 2016, 102, pp. 40-48.
[11] Narendiranath, B.T., Himamshu, H.S., Prabin, K.N., Rama, P.D., Nishant, C.: 'Journal Bearing Fault Detection Based on Daubechies Wavelet'Arch. Acoust., 2017, 42, (3).

[12] Amirat, Y., Benbouzid, M.E.H., Wang, T., Bacha, K., Feld, G.: 'EEMD-based notch filter for induction machine bearing faults detection'Appl. Acoust., 2018, 133.

[13] Zamani Hosseinabadi, H., Amirfattahi, R., Nazari, B., Mirdamadi, H.R., Atashipour, S.A.: 'GUW-based structural damage detection using WPT statistical features and multiclass SVM'Appl. Acoust., 2014, 86, pp. 59-70.

[14] Cox, R.W., Mostafavi, S.: 'Detecting generalized roughness faults in synchronous-generator bearings using the energy in the current spectrum', in '2017 IEEE International Electric Machines and Drives Conference (IEMDC)' (IEEE, 2017), pp. 1-7

[15] Guttormsson, S.E., Marks, R.J., El-Sharkawi, M.A., Kerszenbaum, I.: 'Elliptical novelty grouping for online short-turn detection of excited running rotors'IEEE Trans. Energy Convers., 1999, 14, (1), pp. 16-22.

[16] Cuevas, M., Romary, R., Lecointe, J.-P., Morganti, F., Jacq, T.: 'Non-invasive detection of winding shortcircuit faults in salient-pole synchronous machine', in '2017 IEEE International Electric Machines and Drives Conference (IEMDC)' (IEEE, 2017), pp. 1-7

[17] Skrickij, V., Bogdevičius, M., Junevičius, R.: 'Diagnostic features for the condition monitoring of hypoid gear utilizing the wavelet transform'Appl. Acoust., 2016, 106, pp. 51-62.

[18] Wenxian Yang, Tavner, P.J., Crabtree, C.J., Wilkinson, M.: 'Cost-Effective Condition Monitoring for Wind Turbines'IEEE Trans. Ind. Electron., 2010, 57, (1), pp. 263-271.

[19] Cuevas, M., Romary, R., Lecointe, J.-P., Jacq, T.: 'Non-Invasive Detection of Rotor Short-Circuit Fault in Synchronous Machines by Analysis of Stray Magnetic Field and Frame Vibrations'IEEE Trans. Magn., 2016, 52, (7), pp. 1-4.

[20] Ghanbari, T.: 'Autocorrelation function-based technique for stator turn-fault detection of induction motor'IET Sci. Meas. Technol., 2016, 10, (2), pp. 100-110.

[21] Montazeri, A., Poshtan, J.: 'GA-based optimization of a MIMO ANC system considering coupling of secondary sources in a telephone kiosk'Appl. Acoust., 2009, 70, (7), pp. 945-953.

[22] Montazeri, A., Poshtan, J.: 'Optimizing a MultiChannel ANC System for Broadband Noise Cancellation in a Telephone Kiosk Using Genetic Algorithms'Shock Vib., no date, 16, (3), pp. 241-260.

[23] Salah, M., Bacha, K., Chaari, A., Benbouzid, M.E.H. 'Brushless Three-Phase Synchronous Generator Under Rotating Diode Failure Conditions'IEEE 
Trans. Energy Convers., 2014, 29, (3), pp. 594-601.

[24] Troy, N., Denny, E., O’Malley, M.: 'Base-load cycling on a system with significant wind penetration'IEEE Trans. Power Syst., 2010, 25, (2), pp. 1088-1097.

[25] Konar, P., Chattopadhyay, P.: 'Multi-class fault diagnosis of induction motor using Hilbert and Wavelet Transform'Appl. Soft Comput., 2015, 30, pp. 341-352.

[26] Chen, J., Pan, J., Li, Z., Zi, Y., Chen, X.: 'Generator bearing fault diagnosis for wind turbine via empirical wavelet transform using measured vibration signals'Renew. Energy, 2016, 89, pp. 80-92.

[27] Abed, W., Sharma, S., Sutton, R., Motwani, A.: 'A Robust Bearing Fault Detection and Diagnosis Technique for Brushless DC Motors Under Nonstationary Operating Conditions'J. Control. Autom. Electr. Syst., 2015, 26, (3), pp. 241-254.

[28] Kocaman, Ç., Özdemir, M., Ozdemir, M. 'Comparison of statistical methods and wavelet energy coefficients for determining two common PQ disturbances: Sag and swell', in 'Electrical and Electronics Engineering, 2009. ELECO 2009. International Conference on' (2009), pp. 80-84

[29] Shensa, M.J.: 'The discrete wavelet transform: wedding the a trous and Mallat algorithms'IEEE Trans. Signal Process., 1992, 40, (10), pp. 2464-2482.

[30] Guo, L., Rivero, D., Seoane, J.A., Pazos, A.: 'Classification of EEG signals using relative wavelet energy and artificial neural networks', in 'Proceedings of the first ACM/SIGEVO Summit on Genetic and Evolutionary Computation - GEC '09' (ACM Press, 2009), p. 177

[31] Akin, M.: 'Comparison of Wavelet Transform and FFT Methods in the Analysis of EEG Signals'J. Med. Syst., 2002, 26, (3), pp. 241-247.

[32] Cortes, C., Vapnik, V.: 'Support-vector networks'Mach. Learn., 1995, 20, (3), pp. 273-297.

[33] Schölkopf, B., Smola, A.J.: 'Learning with kernels : support vector machines, regularization, optimization, and beyond' (MIT Press, 2002)

[34] Guler, I., Ubeyli, E.D.: 'Multiclass Support Vector Machines for EEG-Signals Classification'IEEE Trans. Inf. Technol. Biomed., 2007, 11, (2), pp. 117126.

[35] Rafiee, J., Tse, P.W., Harifi, A., Sadeghi, M.H.: 'A novel technique for selecting mother wavelet function using an intelli gent fault diagnosis system'Expert Syst. Appl., 2009, 36, (3), pp. 4862-4875.

[36] Konar, P., Chattopadhyay, P.: 'Bearing fault detection of induction motor using wavelet and Support Vector Machines (SVMs)'Appl. Soft Comput., 2011, 11, (6), pp. 4203-4211.

[37] Bouzida, A., Touhami, O., Ibtiouen, R., Belouchrani, A., Fadel, M., Rezzoug, A.: 'Fault Diagnosis in
Industrial Induction Machines Through Discrete Wavelet Transform'IEEE Trans. Ind. Electron., 2011, 58, (9), pp. 4385-4395.

[38] Zhen, L., Zhengjia, H., Yanyang, Z., Yanxue, W.: 'Customized wavelet denoising using intra- and interscale dependency for bearing fault detection'J. Sound Vib., 2008, 313, (1-2), pp. 342-359.

[39] Seshadrinath, J., Singh, B., Panigrahi, B.K.: 'Vibration Analysis Based Interturn Fault Diagnosis in Induction Machines'IEEE Trans. Ind. Informatics, 2014, 10, (1), pp. 340-350.

[40] Asfani, D.A., Muhammad, A.K., Syafaruddin, Purnomo, M.H., Hiyama, T.: 'Temporary short circuit detection in induction motor winding using combination of wavelet transform and neural network'Expert Syst. Appl., 2012, 39, (5), pp. 53675375 .

[41] Douglas, H., Pillay, P., Barendse, P.: 'The detection of interturn stator faults in doubly-fed induction generators', in 'Fourtieth IAS Annual Meeting. Conference Record of the 2005 Industry Applications Conference, 2005.' (IEEE, no date), pp. 1097-1102

[42] Tafreshi, R., Sassani, F., Ahmadi, H., Dumont, G.: 'Local discriminant bases in machine fault diagnosis using vibration signals'Integr. Comput. Aided. Eng., 2005, 12, (2), pp. 147-158.

[43] Al-Badour, F., Sunar, M., Cheded, L.: 'Vibration analysis of rotating machinery using time-frequency analysis and wavelet techniques'Mech. Syst. Signal Process., 2011.

[44] Gangsar, P., Tiwari, R.: 'Multifault Diagnosis of Induction Motor at Intermediate Operating Conditions Using Wavelet Packet Transform and Support Vector Machine'J. Dyn. Syst. Meas. Control, 2018, 140, (8), p. 081014. 